Tropical Journal of Pharmaceutical Research September 2015; 14 (9): 1643-1649

ISSN: 1596-5996 (print); 1596-9827 (electronic)

(C) Pharmacotherapy Group, Faculty of Pharmacy, University of Benin, Benin City, 300001 Nigeria.

All rights reserved.

Available online at http://www.tjpr.org

Original Research Article

http://dx.doi.org/10.4314/tjpr.v14i9.14

\title{
Protective Effects of Dimedone Pyrone on Podocytes in Rats with Diabetic Nephropathy
}

\author{
Bing-Guo Luan* and Cai-Xia Sun \\ Department of Endocrinology, Yantaishan Hospital, Yantai 264000, Shandong Province, China
}

${ }^{*}$ For correspondence: Email: bingguo73@gmail.com; Tel/Fax: 0086-535-6602001

Received: 19 January 2015

Revised accepted: 25 July 2015

\begin{abstract}
Purpose: To investigate the effect of dimedone pyrone (DP) on podocytes in rats with diabetic nephropathy (DN).

Methods: The rats were randomly assigned into 5 experimental groups $(n=10)$, viz, non-diabetic control with no treatment (ND/NT), diabetic with no treatment (DG/NT), diabetic treated with $5 \mathrm{mg} / \mathrm{kg}$ dimedone pyrone (DG/DP 5), diabetic treated with $10 \mathrm{mg} / \mathrm{kg}$ dimedone pyrone (DG/DP 10) and diabetic treated with $20 \mathrm{mg} / \mathrm{kk}$ dimedone pyrone (DG/DP 20) group. Clinical parameters, including $24 \mathrm{~h}$ urinary protein, blood urea nitrogen (BUN), serum creatinine (SCR), blood glucose (GLU), and kidney weight $(\mathrm{KW}) /$ body weight $(\mathrm{BW})$ were determined after 12 weeks of treatment. Hematoxylin and eosin staining was used to examine renal pathological changes while transmission electron microscopy (TEM) was employed for evaluation of structural changes in the podocytes. The expression levels of nephrin and podocin were evaluated using immunofluorescence staining.

Results: Dimedone pyrone caused a significant decrease in SCR, BUN, GLU, KW/BW and 24 h urine protein in DG/DP 20 group compared to DG/NT group. Furthermore, incidences of glomerular disorders, chronic tubulo-interstitial damage and glomerular podocyte lesions decreased significantly following dimedone pyrone treatment. Glomeruli, tubules and podocytes exhibited pathomorphological improvements while nephrin and podocin protein expression levels were significantly higher in the nephridial tissue. Decrease in relative kidney weight (KW/BW) and $24 \mathrm{~h}$ urinary protein level were improved significantly on treatment with dimedone pyrone. Moreover, glomerular disorder, chronic tubulo-interstitial damage and glomerular podocyte lesions were also suppressed. The improvement was more significant in DG/DP 20 compared to DG/DP 5 and DG/DP 10 groups.

Conclusion: Dimedone pyrone exhibits a protective effect on the podocytes of rats and may be of therapeutic importance in the treatment of diabetic nephropathy.
\end{abstract}

Keywords: Dimedone pyrone, Podocin, Diabetic neuropathy, Nephrin, Glomerular disorders

\begin{abstract}
Tropical Journal of Pharmaceutical Research is indexed by Science Citation Index (SciSearch), Scopus, International Pharmaceutical Abstract, Chemical Abstracts, Embase, Index Copernicus, EBSCO, African Index Medicus, JournalSeek, Journal Citation Reports/Science Edition, Directory of Open Access Journals (DOAJ), African Journal Online, Bioline International, Open-J-Gate and Pharmacy Abstracts
\end{abstract}

\section{INTRODUCTION}

Diabetic nephropathy (DN) is the main cause of end-stage renal disease (ESRD) and the disease is expected to increase in the coming years [1,2]. More than $30 \%$ of all diabetic patients develop diabetic nephropathy (DN) [3], which is the most frequent cause of chronic kidney disease (CKD) and risk factor for stroke and heart attack [4]. The number of diabetic patients and those affected by DN is rapidly increasing [5]. Not all diabetic patients develop DN and the development and severity of DN vary greatly from one patient to another with familial clustering, suggesting that genetic factors play an important role [6].

The expensiveness of renal replacement therapy makes it unaffordable even for developed 
countries [7]. Diabetic nephropathy also leads to glomerulosclerosis and ESRD worldwide in its advanced stage $[8,9]$. DN manifests as a clinical syndrome that is composed of albuminuria, progressively declining glomerular filtration rate (GFR) and increased risk for cardiovascular disease $[10,11]$. Persistent proteinuria is the hallmark of diabetic nephropathy which is the leading cause of end-stage renal disease. Furthermore, a reduction in proteinuria is associated with a slowing of both the decline in the GFR and the progression to ESRD. As a result, a reduction in proteinuria has been widely used as a surrogate end point for renoprotection.

Pyrones are reported to exhibit a wide range of biological activities which include antimicrobial, antimalarial, anti-nematodal activities as well as calmodulin-dependent, estrogenic and antiestrogenic, and acetylcholinesterase (AChE) inhibitory activities [12-14]. In the present study the effect of dimedone pyrone (Fig. 1) on podocytes in rats with diabetic nephropathy (DN) was investigated.

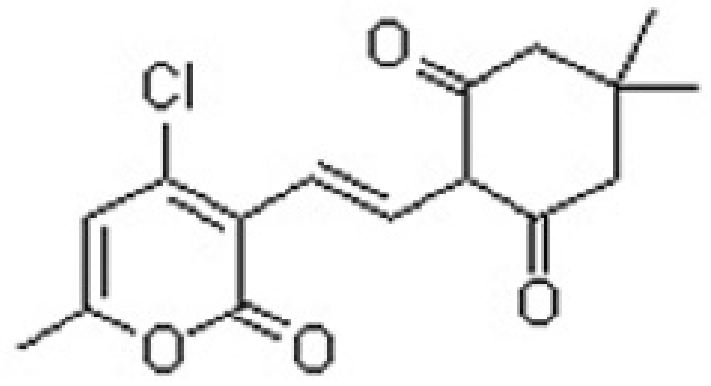

Fig 1: Structure of dimedone pyrone

\section{EXPERIMENTAL}

\section{Animals}

Fifteen week old male, adult Sprague Dawley rats (weighing around $200 \mathrm{~g}$ ) from Chengdu Dashuo Biological Technology Co, Ltd, Chengdu, China were maintained in pathogen-free conditions and fed irradiated chow.

\section{Reagents and instruments}

Dimedone pyrone, TWP, and alloxan were purchased from Sigma-Aldrich (St. Louis, MO, USA). Rat urine albumin EIA assay kit, rabbit anti-rat nephrin antibodies, rabbit anti-rat podocin antibodies and goat anti-rabbit antibodies were obtained from Boster (Tarivid; Santen, Osaka, Japan). Accu-chek Blood glucose meter from Roche Diagnostics GmbH (Tarivid; Santen, Osaka, Japan) and 7150 automatic biochemical analyzer from Hitachi (BD Biosciences, Franklin
Lakes, NJ, USA). The JEOL-1230 transmission electron microscope was obtained from JEOL (BD Biosciences, Franklin Lakes, NJ, USA), Vanox multifunctional microscope was purchased from Olympus (BD Biosciences, Franklin Lakes, NJ, USA) and SDS-PAGE electrophoresis was obtained from Bio-Rad (Hercules, CA, USA).

\section{Grouping and drug administration}

After 15 days of acclimatization to laboratory environment, the rats were fasted $12 \mathrm{~h}$ prior to the experiment. Rats were randomly assigned into 5 experimental groups, with 10 animals each, as follows: Non-diabetic control (ND/NT) group consisting of normal rats without any treatment; Diabetic control (DG/NT) group consisting of diabetic rats without any treatment; Diabetic (DG/DP $5 \mathrm{mg}$ ) group consisting of diabetic rats treated with dimedone pyrone 5 $\mathrm{mg} / \mathrm{kg}$; Diabetic (DG/DP $10 \mathrm{mg}$ ) group consisting of diabetic rats treated with $10 \mathrm{mg}$ dimedone $/ \mathrm{kg}$ body weight and Diabetic (DG/DP $20 \mathrm{mg} / \mathrm{kg}$ ) group consisting of diabetic rats treated with dimedone pyrone $20 \mathrm{mg} / \mathrm{kg}$. The dimedone pyrone was administered intraperitoneally to the rats. During fasting alloxan was injected through tail veins at a dose of $42 \mathrm{mg} / \mathrm{kg}$ of body weight to four animal groups and $72 \mathrm{~h}$ latter blood samples were collected to measure blood glucose concentrations. The blood glucose in rats was maintained $\geq 16.7 \mathrm{mmol} / \mathrm{L}$. The rats were weighed weekly to adjust the dose and dimedone pyrone was continuously administered for 12 weeks. During the experiment, the rats were fed a standard diet and were free to drink water. Use of laboratory animals was approved by the Local Committee on Animal Use and Protection and performed in accordance with the National Institutes of Health Guide for the Care (ref no: 2014-123).

\section{Specimen collection}

On the last day of experiment urine was collected for $24 \mathrm{~h}$, centrifuged and stored at $80{ }^{\circ} \mathrm{C}$. Through right common carotid artery blood samples were collected half of the samples were put in anticoagulant tubes and the rest was centrifuged. The plasma was stored at $20{ }^{\circ} \mathrm{C}$. Weight of the animals was also recorded. The animals were anaesthetized and after sacrifice, kidney tissues were fixed in $4 \%$ paraformaldehyde solution and embedded in paraffin. The paraffin-embedded kidney tissues were cut into $3 \mu \mathrm{m}$ thick sections. For immunofluorescence examination the sections were treated with polylysine whereas for transmission electron microscopic studies $1 \mathrm{~mm}$ 
sections were put in ethanol at $4{ }^{\circ} \mathrm{C}$ for $2 \mathrm{~h}$ before examination.

\section{Analysis of biochemical parameters}

Rat urine albumin EIA assay kit was used for 24 $\mathrm{h}$ urinary protein concentration determination as per the manufacturer's instructions. Clinical parameters like body weight, feed intake, water intake, and diuresis were recorded for every individual metabolic cage. The biochemical parameters including serum creatinine (SCR), blood urea nitrogen (BUN), aspartate aminotransferase (AST) and alanine aminotransferase (ALT) were detected in the serum using a 7150 automatic biochemical analyzer. Johnson \& Johnson's standard enzymatic method was used for blood glucose determination.

\section{Examination of renal tissue under light microscopy}

Two mm sections of left kidney were fixed in 10 $\%$ formaldehyde and embedded in paraffin. The paraffin embedded sections were cut into $1 \mu \mathrm{m}$ thick sections and after de-paraffinization were stained with hematoxylin and eosin (HE). The sections were subjected to light microscopy for pathological changes.

\section{Ultrastructural changes}

For examination of ultrastructural changes tissue specimens were cut into sections and washed in phosphate buffer followed by post fixation in glutaraldehyde. The tissues, after dehydration in graded acetone concentrations, were embedded in Araldite, cut into very thin sections, stained with uranyl acetate and aluminium citrate for examination under a JEOL 1230 transmission electron microscope.

\section{Distribution of nephrin and podocin}

The paraffin embedded tissues were cut into 1 $\mathrm{mm}$ thin sections, de-paraffinized and incubated overnight with rabbit anti rat nephrin (1:400) and rabbit anti rat podocin $(1: 400)$ antibodies at $4{ }^{\circ} \mathrm{C}$. After washing in phosphate buffer the slices were treated with fluorescein isothiocyanate labeled goat, anti rabbit and antibodies observed under immunofluorescence microscopy.

\section{Statistical analysis}

All the results are expressed as mean \pm standard deviation (SD). SPSS 11.0 software package (SPSS, Inc, Chicago, IL, USA) was used for statistical analysis of the data. Differences were considered statistically significant at $p<0.05$.

\section{RESULTS}

\section{Effect of dimedone pyrone on proteinuria in rats with DN}

Examination of $24 \mathrm{~h}$ proteinuria in all the five groups of animals revealed a significantly higher level in DG/NT group compared to that in ND/NT and DG/DP 20 groups (Fig. 2). The $24 \mathrm{~h}$ proteinuria in DG/DP 10 group was lower than DG/VT 5 group which in turn showed the level comparable to that of DG/DP 20 (Fig. 2).

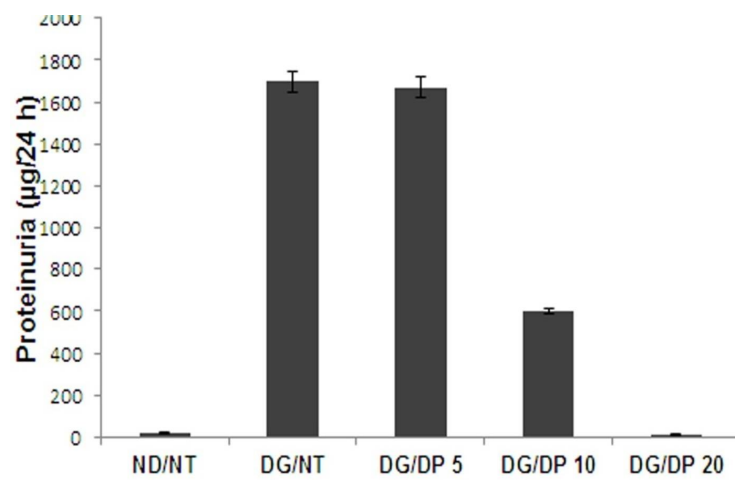

Fig. 2: The $24 \mathrm{~h}$ urine protein level comparison of nondiabetic, diabetic and dimedone pyrone treated diabetic rats

\section{Effect of dimedone pyrone on kidney weight/body weight (KW/BW) in DN}

After 12 weeks of treatment it was observed that compared to ND/NT group, the KW/BW ratios in DG/NT group was higher $(p<0.01)$ and that in DG/DP 20 group was significantly lower (Fig. 3). However the KW/BW ratio in DG/DP 5 group was slightly lower than that of DG/NT group.

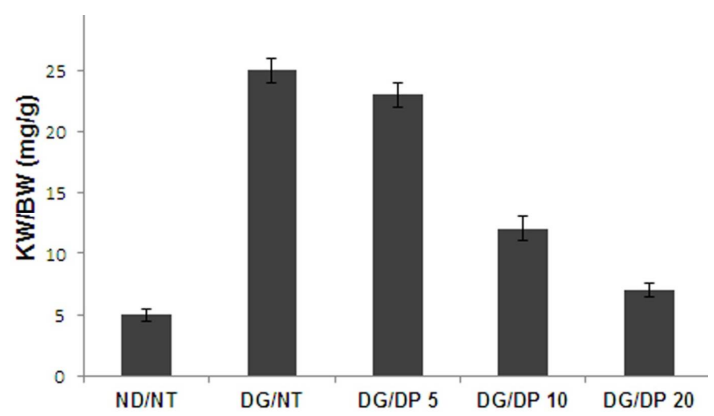

Fig. 3: Relative kidney weight (KW/BW ratios) comparison of non-diabetic, diabetic and dimedone pyrone treated diabetic rats 
Effect of dimedone pyrone on serum biochemistry parameters of $\mathrm{DN}$ rats

In DG/NT group the SCR, BUN and fasting glucose levels were significantly higher $(p<0.05)$ compared to ND/NT group (Table 1).

\section{Change of renal tissue pathology of DN}

In DG/NT group the HE stained renal biopsy samples exhibited tubular deformation and glomerular hypertrophy. However dimedone pyrone treated animals showed a marked decrease in tubular deformation and glomerular hypertrophy on treatment with $20 \mathrm{mg} / \mathrm{kg}$ body weight of dimedone pyrone after 12 weeks (Fig 4).

\section{Effect of podocyte disease on DN rats}

Compared to NG/NT group, the animals in DG/NT group showed abnormal morphological appearance of podocytes like fusion and decrease in foot processes. Treatment with dimedone pyrone caused a reversal of alloxan induced effect on podocytes. Although the reversal of effect started at a concentration of 5 $\mathrm{mg} / \mathrm{kg}$ body weight but was significant at 20 $\mathrm{mg} / \mathrm{kg}$ in DG/DP 20 group (Fig. 5).

Table 1: Dimedone pyrone improves SCR, BUN and fasting glucose levels

\begin{tabular}{lccccc}
\hline Group & $\begin{array}{c}\text { Glucose } \\
\text { (mmol/L) }\end{array}$ & BUN(mmol/L) & SCr( $\boldsymbol{\mu m o l / L )}$ & AST (U/L) & ALT (U/L) \\
\hline ND/NT & $5.02 \pm 0.56$ & $5.98 \pm 0.67$ & $66.90 \pm 4.88$ & $58.23 \pm 8.75$ & $53.65 \pm 6.59$ \\
DG/NT & $25.14 \pm 3.83$ & $11.26 \pm 1.86$ & $95.57 \pm 10.76$ & $70.43 \pm 8.46$ & $78.79 \pm 2.53$ \\
DG/DP 5 & $23.23 \pm 2.78$ & $10.67 \pm 1.48$ & $91.23 \pm 10.43$ & $68.65 \pm 7.98$ & $70.23 \pm 5.11$ \\
DG/DP 10 & $18.02 \pm 1.98$ & $8.27 \pm 1.74$ & $74.12 \pm 10.27$ & $63.42 \pm 8.12$ & $61.67 \pm 7.65$ \\
DG/DP 20 & $6.45 \pm 1.06$ & $6.91 \pm 1.58$ & $68.51 \pm 10.96$ & $59.84 \pm 7.93$ & $54.78 \pm 6.43$ \\
\hline
\end{tabular}

The results are mean $\pm S D$. Key: Glu, glucose; BUN, blood urea nitrogen; Cr, creatinine; AST, aspartate aminotransferase; $A L T$, alanine aminotransferase; $W B C$, white blood cell

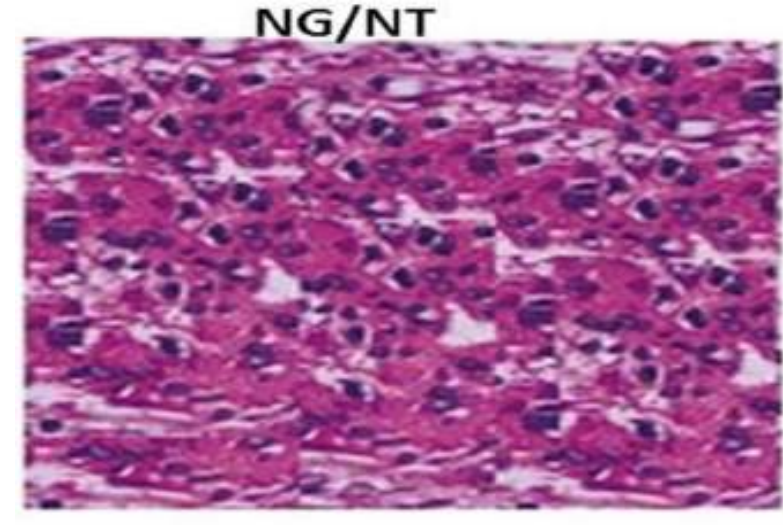

DG/DP 10

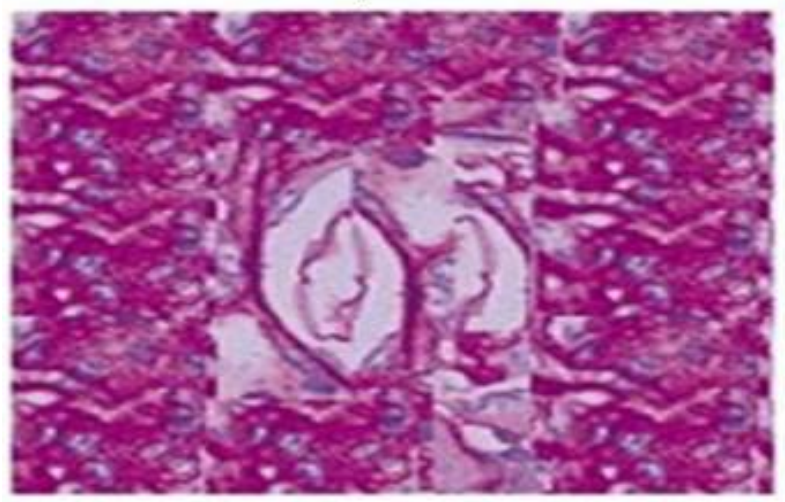

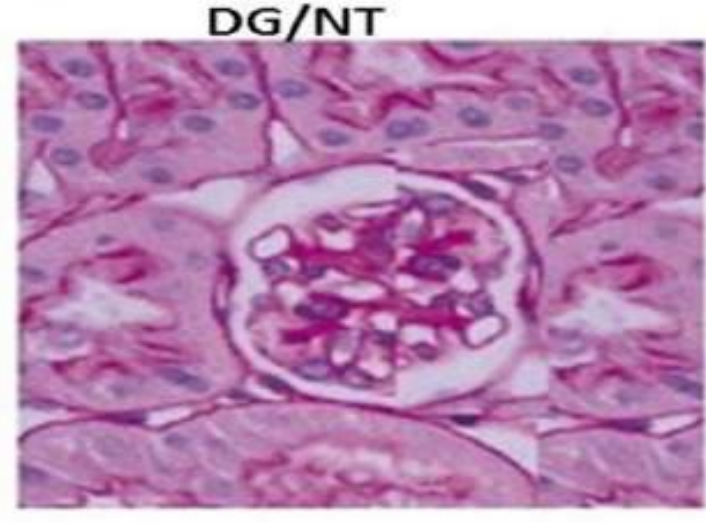

DG/DP 20

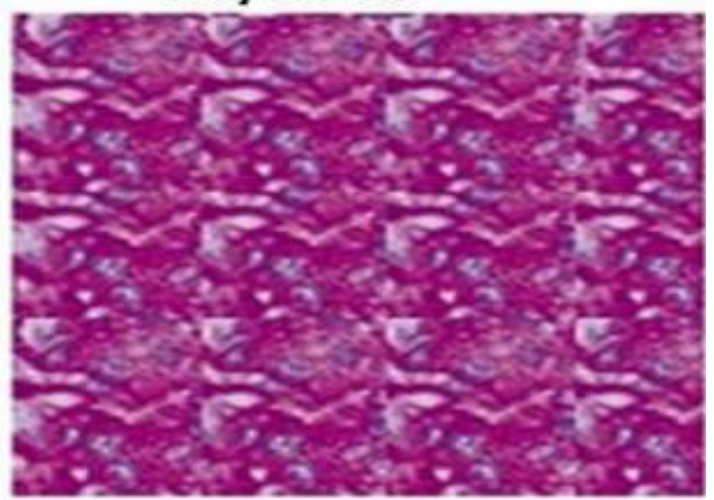

Fig 4: Renal pathological changes in control and dimedone pyrone-treated DN rats ND/NT, non-diabetic control no treatment; DG/NT, diabetic no treatment, DG/DP 5 , diabetic group treated with $5 \mathrm{mg} / \mathrm{kg}$ dimedone pyrone treated and DG/DP 10, diabetic group treated with $10 \mathrm{mg} / \mathrm{kg}$ dimedone pyrone and DG/DP 20, diabetic group treated with $20 \mathrm{mg} / \mathrm{kg}$ dimedone purone 
NG/NT

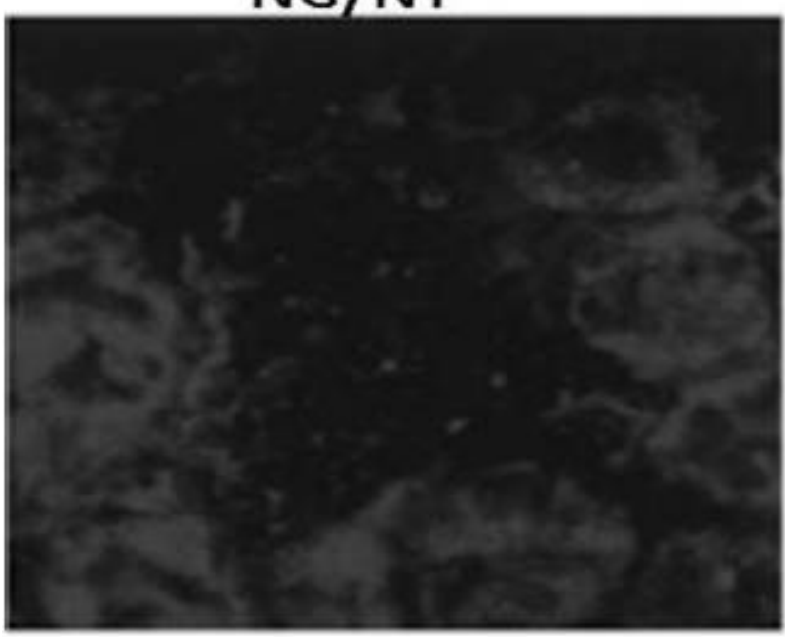

DG/DP 10

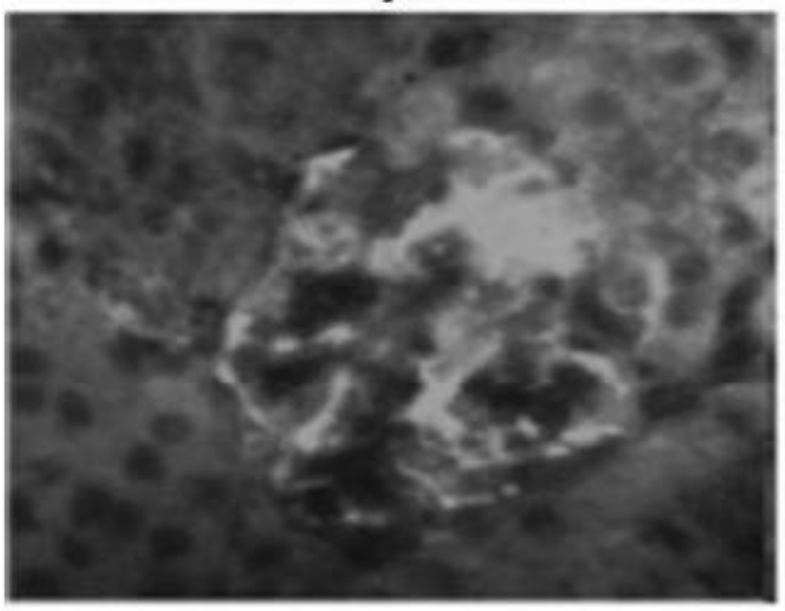

DG/NT

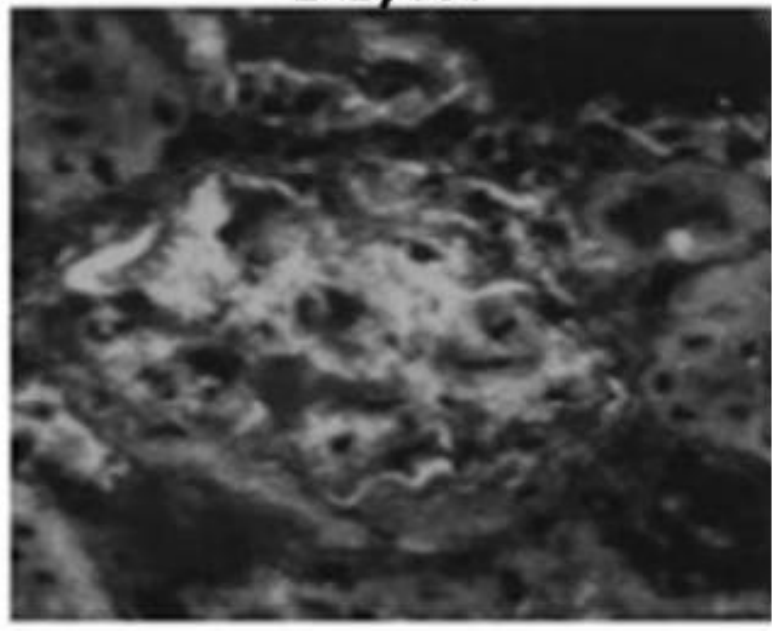

DG/DP 20

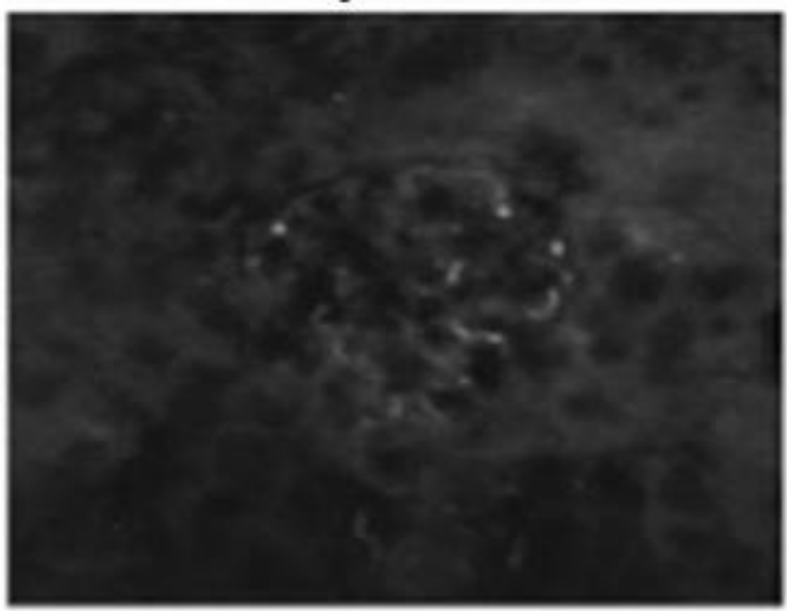

Fig 5: Podocyte lesions using electron microscopy in DN rats. ND/NT, non-diabetic control no treatment; DG/NT, diabetic no treatment, DG/DP 5, diabetic group treated with $5 \mathrm{mg} / \mathrm{kg}$ dimedone pyrone treated and DG/DP 10, diabetic group treated with $10 \mathrm{mg} / \mathrm{kg}$ dimedone pyrone and DG/DP 20, diabetic group treated with $20 \mathrm{mg} / \mathrm{kg}$ dimedone purone

\section{Nephrin and podocin protein expression}

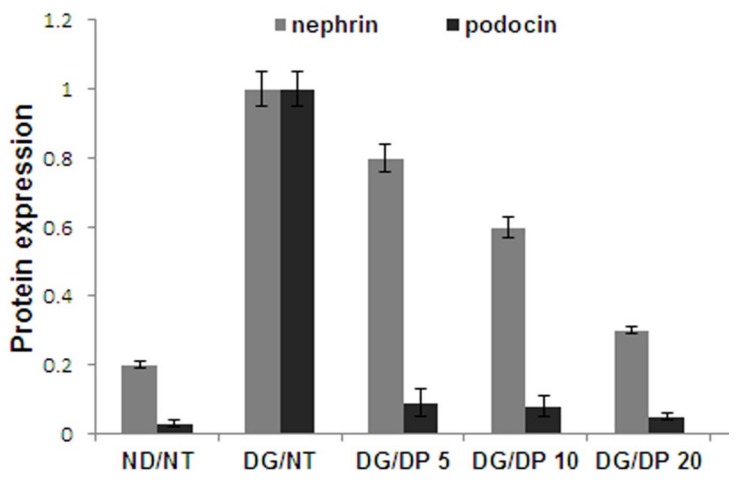

Fig 6: Expression of nephrin and podocin proteins in podocytes of DN rats. ND/NT, non-diabetic control no treatment; DG/NT, diabetic no treatment, DG/DP 5, diabetic group treated with $5 \mathrm{mg} / \mathrm{kg}$ dimedone pyrone treated and DG/DP 10, diabetic group treated with 10 $\mathrm{mg} / \mathrm{kg}$ dimedone pyrone and DG/DP 20, diabetic group treated with $20 \mathrm{mg} / \mathrm{kg}$ dimedone purone

In DG/NT group of rats, nephrin and podocin protein expression levels were significantly low compared to NG/NT group. Treatment with dimedone pyrone increased the level of nephrin and podocin protein expression. The increase in expression was significant and comparable to that of NG/NT group at a concentration of 20 $\mathrm{mg} / \mathrm{kg}$ body weight in DG/DP 10 group (Fig 6).

\section{DISCUSSION}

It is reported that proteinuria on accumulation in mesangial cells enhances glomerular sclerosis $[15,16]$. Urinary proteins also regulate tubular cell 
function, which changes the growth characteristics of cytokines and matrix proteins, as well as their phenotypic expression and induction of fibrosis [17]. The present study demonstrates that dimedone pyrone decreases the level of proteinuria in the DN rats.

Changed podocyte ultrastructure and associated molecules induce DN proteinuria [18,19]. Microalbuminuria in DN decreases podocyte count which leads to compensatory hypertrophy to cover basement membrane, thereby increasing permeability. These changes produce abundant proteinuria and subsequently increase podocyte injury. Detachment of podocytes exposes the basement membrane and damage fenestrated membrane and allows large number of proteins to pass [14]. This ultimately leads to glomerular sclerosis and progressive loss of renal function [20]. The results from our study showed that dimedone pyrone at a concentration of $20 \mathrm{mg} / \mathrm{kg}$ body weight in rats reversed the effect of damage caused to podocytes in DN rats.

Slit diaphragm (SD) is the main barrier which filters protein macromolecules and is composed of neph 1, nephrin, podocin and FAT1 [21]. In animal experiments, researchers have found that DM worsens kidney damage in rats, reduces nephrin expression and increases albuminuria in urine [22]. The decreased expression of nephrin preceded glomerular tissue damage and is an early event in DN. In the DN model, changes in podocin were associated with protein and mRNA expression levels of nephrin [23].

We observed that dimedone pyrone treatment decreased glomerular hypertrophy and tubular deformation in DN rats after 12 weeks. There was also a decrease in fusion of the podocyte foot processes, disappearance of membrane slits and reduced number of slits in DG/DP group of rats. Dimedone pyrone also increased the expression level of nephrin and podocin in DG/DP 5 and DG/DP 10 groups. However, the increase was significant in DG/DP 20 group.

\section{CONCLUSION}

Dimedone pyrone exhibits a protective effect on the podocytes of rats and can be of therapeutic importance in the treatment of diabetic nephropathy.

\section{REFERENCES}

1. Stern M. Diabetes and cardiovascular disease. The "common soil" hypothesis. Diabetes 1995; 44: 369374.
2. Eastman $R$, Siebert $C$, Harris M, Gorden P. Clinical review: implications of the Diabetes Control and complications trial. J Clin Endocrinol Metab 1993; 77: 1105-1107.

3. Perkins BA, Krolewski AS. Early nephropathy in type 1 diabetes: a new perspective on who will and who will not progress. Curr Diab Rep 2005; 5: 455-463.

4. Brown WV. Microvascular complications of diabetes mellitus: renal protection accompanies cardiovascular protection. Am J Cardiol 2008; 102: 10-13.

5. Williams ME. Diabetic CKD/ESRD 2010: A progress report. Semin Dial 2010; 23: 129-133.

6. Bowden DW. Genetics of diabetes complications. Curr Diab Rep 2002; 2: 191-200.

7. Turner R. The U.K. Prospective Diabetes Study. A review. Diabetes Care 1998; 21: C35-C38.

8. Clark CJ, Lee D. Prevention and treatment of the complications of diabetes mellitus. N Engl $J$ Med 1995; 332: 1210-1217.

9. Fore W. Noninsulin-dependent diabetes mellitus. The prevention of complications. Med Clin North Am 1995; 79: 287-298.

10. Remuzzi G, Ruggenenti P, Benigni A. Understanding the nature of renal disease progression. Kidney Int 1997; 51: 2-15.

11. Parving HH, Osterby R, Ritz E. Diabetic Nephropathy. The Kidney, edited by Brenner BM, Philadelphia, WB Saunders 2000; $p 1731$.

12. Meng X, Mao Z, Lou J, Xu L, Zhong L, Peng Y.; Zhou, L, WangM. Benzopyranones from the endophytic fungus Hyalodendriella sp. Ponipodef12 and their bioactivities. Molecules 2012; 17: 11303-11314.

13. Zhong, L, Xu L, Meng X, Peng Y, Chen Y, Sui P, Wang $M$, Zhou $L$. Botrallin from the endophytic fungus Hyalodendriella sp. Ponipodef12 and its antimicrobial activity. Afr. J. Biotechnol. 2011; 10: 18174-18178.

14. Jeon YT, Ryu KH, Kang MK, Park SH, Yun $H$, Qt P, Kim SU. Alternariol monomethyl ether and $\alpha, \beta$ dehydrocurvularin from endophytic fungi Alternaria spp. Inhibit appressorium formation of Magnaporthe grisea. J. Korean Soc. Appl. Biol. Chem. 2010; 53: 39-42.

15. Benigni A, Coma D, Zoja C. Targeted deletion of angiotensin II type $1 \mathrm{~A}$ receptor does not protect mice from progressive nephropathy of overload proteinuria. J Am Soc Nephrol 2004; 15: 2666-2674.

16. Morigi M, Buelli S, Angioletti $S$. In response to protein load podocytes reorganize cytoskeleton and modulate endothelin-1 gene: implication for permselective dysfunction of chronic nephropathies. Am J Pathol 2005; 166: 1309-1320.

17. Zou Z, Chung B, Nguyen T. Linking receptor-mediated endocytosis and cell signaling: evidence for regulated intramembrane proteolysis of megalin in proximal tubule. J Biol Chem 2004; 279: 343102-34310.

18. Koop K, Eikmans M, Baelde HJ. Expression of podocyte associated molecules in acquired human kidney diseases. J Am Soc Nephrol 2003; 14: 20632071.

Trop J Pharm Res, September 2015; 14(9): 1648 
19. Toyoda M, Najafian B, Kim Y, Caramori ML, Mauer M. Podocyte detachment and reduced glomerular capillary endothelial fenestration in human type 1 diabetic nephropathy. Diabetes 2007; 56: 21552160.

20. Liu ZH, Li SJ, Chen C, Zeng C, Zhang B, Zhou H, Li L. Glomerular podocyte lesion in patients with diabetic nephropathy. Shen Zang Bing Yu Tou Xi Shen Yi Zhi Za Zhi 2003; 12: 144148.
21. Barisoni $L$ and Koppb BJ. Update in podocyte biology: putting one's best foot forward. Curr Opin Nephrol Hypertens 2003; 12: 251-258.

22. Benzing T. Signaling at the slit diaphragm. J Am Soc Nephrol 2004; 15: 13821391.

23. Langham RG, Kelly DJ, Cox AJ. Proteinuria and the expression of the podocyte slit diaphragm protein, nephrin, in diabetic nephropathy: effects of angiotensin converting enzyme inhibition. Diabetologia 2002; 45: 15721576. 